\title{
Learners' preferences towards Corrective feedback in writing assignments in tertiary education
}

\author{
Jolita Horbacauskiene \& Ramune Kasperaviciene \\ Kaunas University of Technology \\ Kaunas, Lithuania
}

\begin{abstract}
For several decades, there has been a heated debate about the value of providing corrective feedback in writing assignments in English as a foreign language (EFL) classes. Despite the fact that corrective feedback in writing has been analysed from various angles, learners' expectations regarding feedback given by language instructors are still to be considered, especially in different learning settings. Student attitudes have been found to be associated with motivation, proficiency, learner anxiety, autonomous learning, etc. (Elwood \& Bode, 2014). Thus, the aim of this paper was to compare EFL learners' attitudes towards corrective feedback and self-evaluation of writing skills in different learning settings. Students at two technological universities in France and Lithuania were surveyed and asked to complete an anonymous questionnaire combining the Likert scale and rank order questions. The results indicate that frequency of writing assignments seems to have little or no impact on students' self-evaluation of writing skills. Moreover, although the two groups of students showed preference for feedback on different error types (e.g., feedback on structure vs. feedback on grammar), nevertheless, indirect corrective feedback with a clue was favoured by all the respondents.
\end{abstract}

Key words: writing assignments; corrective feedback; students' preferences; Lithuanian and French students; writing skills.

\section{Introduction}

Corrective feedback, a long debated issue, is still attracting researchers', theorists' and language practitioners' attention. The effectiveness and usefulness of corrective feedback, the value of corrective feedback for different error types, its harmful effects, as well as selective and comprehensive error treatment and other related issues have been repeatedly studied in search for conclusive evidence for or against its use in foreign language learning/teaching. Some research studies have proposed not to focus on corrective feedback in writing (Lee, 2003; Guenette, 2007) or doubted the long-term effect of corrective form-based feedback (Hyland, 
2003; Ashwell, 2000). Following Truscott's arguments that written corrective feedback is "a clear and dramatic failure" (2007: 271) and is in fact harmful, a plethora of studies have claimed otherwise providing mounting evidence (Bitchener et al, 2005; Bitchener, 2008; Bruton, 2009; Ferris, 2006; Hartshorn et al, 2010; Lee, 2004; Sheen, 2007) that corrective feedback may improve writing accuracy.

Despite the fact that corrective feedback in writing has been analysed from various angles, foreign language learners' expectations regarding feedback given by language instructors are still to be considered, especially in different learning settings. Guenette (2007) claims that research concerning student attitudes and preferences is also of importance among other studies revealing different dimensions of feedback. Therefore, the aim of the paper was to compare EFL learners' attitudes towards corrective feedback and self-evaluation of writing skills in different learning settings. More precisely, the paper investigated what type of corrective feedback students expected to receive (i.e. direct, indirect, indirect with a clue and indirect with a clarification request) and whether self-evaluation of writing skills of students in different learning settings differs. It should be noted that different learning settings might result in different attitudes of students towards language instructor's feedback and different self-evaluation of writing skills. Studying these issues may provide helpful pedagogical implications on possible language instructors' behaviour in giving the most expected feedback by students.

\section{Theoretical background}

Language instructors' feedback can come in two main forms: corrective feedback (grammar, sentence structure, lexical and syntactic complexity, etc.) and contentrelated feedback (ideas expressed, arguments, writing style, etc.). There has been a continuous debate about the value of providing corrective feedback in ESL writing assignments as a result of Truscott's arguments (1996).

The vast majority of recent studies have provided evidence on positive and significant effects of written corrective feedback (Bitchener, 2008; Beuningen, 2010; Ellis et al, 2008). Language instructor provided feedback is considered by both learners and teachers to play a significant role in the writing process (Ferris, 2002; Jamalinesari et al, 2015), although students tend to believe that assessment is a teacher's responsibility.

Language instructors may take the selective (also known as focused) or comprehensive (unfocused) approach towards error treatment when providing corrective feedback. Selective error treatment involves identification and marking of a limited number of error types rather than indicating every grammatical, lexical or spelling error throughout the written text. The majority of studies on the 
approach to error treatment recommend taking a selective approach as it "not only saves time for the language instructor but also potentially allows students to recognise patterns of error within their writing" (McMartin-Miller, 2014: 25). Selective error treatment allows developing students' editing skills, which also fosters second language acquisition because students will most probably better understand the nature of the error and avoid making it in future. As noted by McMartin-Miller (2014), selective error treatment is not simple for language instructors as it is their decision which and how many error types should be marked. Besides, language instructors need to additionally instruct students on the type of corrective feedback provided and how students should proceed in order to revise and correct their written texts, a step which may result in a misunderstanding between language instructors and students. For this reason, the comprehensive approach towards error treatment, in which all errors are marked, might be considered clearer for students although its effectiveness and usefulness is under debate.

Researchers have proposed a few categorisations of types of errors corrected by language instructors: global vs. local (Burt, 1975); global vs. local vs. other (Bates et al, 1993); treatable vs. untreatable (Ferris, 2002); errors vs. mistakes (Corder, 1967). Another possible distinction is supported by Beuningen (2010) who relies on a contrast between grammatical errors and errors outside the grammatical domain, based on Truscott's (2007) argument that corrective feedback could be applied only for relatively simple and discrete errors, such as spelling. All this is closely related to the question of how errors should be corrected. Two major approaches involve direct and indirect error correction. According to Hyland \& Han (2015), direct corrective feedback occurs when a language instructor corrects the error directly and explicitly, providing the correct version. Indirect corrective feedback may take different forms: a language instructor may underline or circle the error, give clues for revision, or underline the error and indicate the ambiguity (Hyland \& Han, 2015).

Learners' expectations may therefore be the critical link between written corrective feedback and learning outcomes as the expectations concerning the feedback provided may determine learners' engagement with that feedback and motivation to learn overall. It may well be that students who assess their writing skills differently expect a different type of corrective feedback provided by a language instructor. Pajares (2003) claims that in fact, teacher feedback has a significant impact on student's perceived self-evaluation of their own writing skills and motivation, which may be negatively affected upon receiving unclear, inaccurate or ineffectively processed feedback (Zumbrunn et al, 2016). Learners who view their own writing skills negatively, may be unwilling to receive corrective feedback, as it may show their shortcomings in writing skills all too well and in turn reduce their motivation. On the other hand, as argued by 
Harward et al. (2014), an appropriate type of feedback may develop students' motivation and effort.

Student attitudes have been found to be associated with motivation, proficiency, learner anxiety, autonomous learning, etc. (Elwood \& Bode, 2014). A number of studies have highlighted positive students' attitudes towards error correction (Chandler, 2003; Cohen \& Cavalcanti, 1990; Ferris \& Roberts, 2001; Leki, 1991). For example, the results obtained by Ferris \& Roberts (2001) indicated the most popular types of feedback are underlining with description, direct correction, and underlining alone. This may be because such error correction was the fastest and easiest way for learners to revise their own corrections. In a study by Chandler (2003), the majority of learners preferred direct explicit correction although they also favoured indirect feedback with a clue as the best way to learn to avoid mistakes in the future. The author argues that extensive studies of a foreign language in the past may not necessarily determine students' ability to identify unmarked or unindicated errors throughout their written text as it may be "too cognitively demanding to identify an error from a description without location" (Chandler, 2003: 292). It seems that direct correction as a possible type of corrective feedback is favoured by both language instructors and learners, as it saves time for the former and affords clarity to the latter. All these insights support the idea that corrective feedback is helpful in facilitating foreign language acquisition.

\section{Methodology}

For the purposes of this research, students at two technological universities in France and Lithuania were surveyed. The sample included randomly selected undergraduate Lithuanian student respondents majoring in technological sciences (N-66) and undergraduate French students majoring in engineering sciences (N58). An anonymous questionnaire combining the Likert scale and rank order questions was composed for students. The questionnaire was designed with reference to the studies by Kahraman \& Yalvac (2015), Diab (2005) and the ESLP 82 questionnaire. Lithuanian and French students were asked to fill the questionnaire (online or paper version) upon or near to the completion of English language level $\mathrm{C} 1$ course. The questionnaire consisted of closed questions: the questions related to self-evaluation of writing skills, instructors' feedback, and students' approach to instructors' feedback.

The major difference between French and Lithuanian students lies in the duration and intensity of their foreign language studies. Language studies at a university in Lithuania are organised for one semester during the first or the second year and students take 5 academic hours per week, leading to 6 ECTS (European Credit Transfer and Accumulation System) credits. Students acquire general language as well as professional language skills; professional language of their major is ac- 
quired through individual work, personal presentations and background reading. The Lithuanian students polled had all achieved first foreign language level C1 required in their 4-year BA programme.

The French students enrolled in a French engineering school are required to achieve the European framework language level C1 in English (as certified by a TOEIC score of 785) within two years before completing their 5-year Engineering programme. Students acquire general language as well as professional language skills; language of their engineering specialisation is acquired through course materials, individual reading, project work and internships. Students have from 20 to 25 hours per semester over 5 semesters averaging about 2.5 academic hours per week.

Statistical data of the research study were processed with SPSS version 22.0 (Statistical Package for Social Sciences) programme using the descriptive statistical method, the Student $t$ test and ANOVA. The internal consistency of the scales was tested using Cronbach's alpha. Overall, Cronbach's alpha for the scale of respondents self-evaluation of their writing skills was $0.93(\mathrm{~N}-16)$, and the scale of respondents' expectation of language instructors' feedback was 0.876 (N-7), which are both above the acceptable level of 0.7 . The Student $t$ test was employed to compare the opinion of two groups of students, namely French and Lithuanian. A one-way ANOVA was run to compare the mean scores of respondents' selfevaluation of writing skills and frequency of writing assignments in EFL classes.

Respondents' self-evaluation of writing skills was measured by the Likert scale where 1 represented never or almost never true of me; 2 - usually not true of me; 3 somewhat true of me; 4 - usually true of me, and 5 - always or almost always true of me. For the purposes of conciseness of data representation, the data of the scale on selfevaluation of writing skills is presented in summed values of 4 - usually true of me and 5 - always or almost always true of me.

\section{Results}

The research results were ranked according to students' opinion in both groups (N-66 Lithuania and N-58 French). The Lithuanian students ranked the statements on the scale about their writing skills as follows: ability to write a logical topic sentence that identifies the topic and controlling idea of a summary (89.4\%); ability to support the main points $(83.3 \%)$; logical organisation of ideas $(81.8 \%)$; ability to support paragraphs with paraphrases $(81.8 \%)$; ability to paraphrase information $(81.6 \%)$; ability to write a draft to logically organise the ideas $(80 \%)$. The lowest ranks were given to the following skills: use of various sentence structures $(57.1 \%)$; usage of appropriate lexical items and forms for effective expression of ideas $(65.1 \%)$; correct usage of spelling, capitalisation and punctuation (65.1\%); ability to review text and improve structure as well as ability to identify and improve 
problems (72.7\% each). The French respondents' agreement was not as high as that of the Lithuanian respondents. The highest ranks were given to the statements: ability to write a logical topic sentence that identifies the topic and controlling idea of a summary (70.7\%); ability to support the main points $(70.7 \%)$; ability to write an appropriate summary of information read (67.3\%); and logical organisation of ideas $(65.5 \%)$. The lowest ranked statements were as follows: ability to write appropriate paragraphs and ability to identify and improve problems $(41.3 \%)$; ability to write a good conclusion (44.8\%); and use of various sentence structures $(47.5 \%)$. The above-mentioned information is graphically represented in Figure 1.

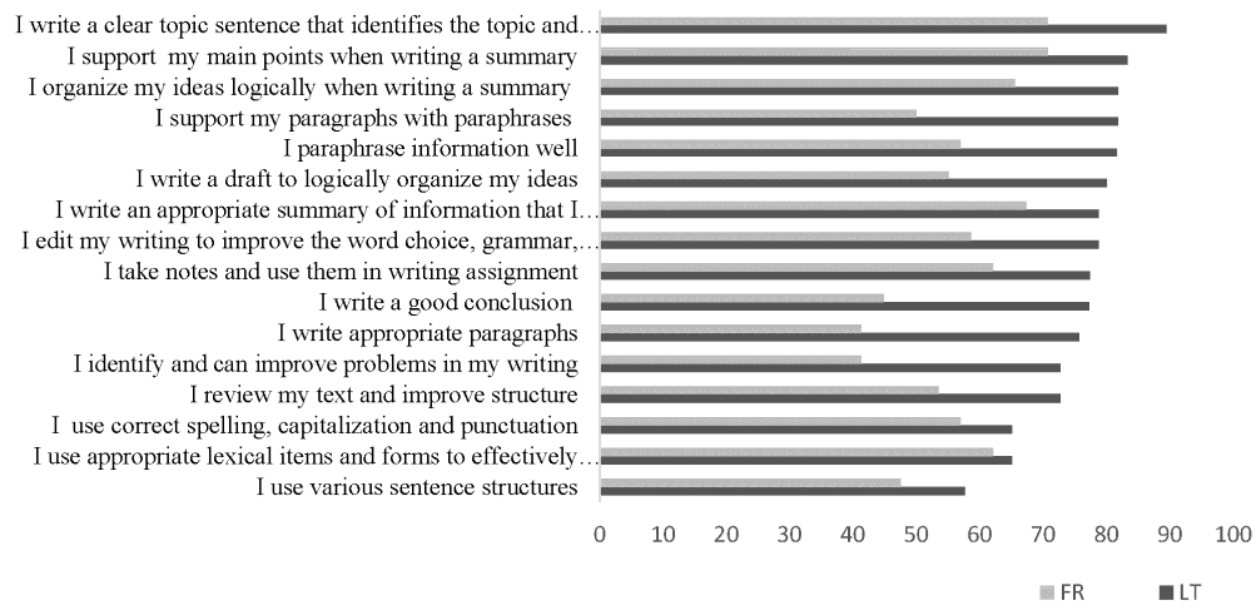

Figure 1. Respondents' self-evaluation of writing skills.

The differences between French and Lithuanian respondents' answers were all statistically significant. The Student $t$ test was employed in order to compare the opinion on the approaches towards writing abilities between French and Lithuanian respondents. Statistically significantly more Lithuanian students agreed with the statements $I$ write appropriate paragraphs $(\mathrm{t}=4.227 ; \mathrm{p}=0.000) ;$ I paraphrase information well $(\mathrm{t}=3.743 ; \mathrm{p}=0.000) ;$ I support my paragraphs with paraphrases $(\mathrm{t}=4.548 ; \mathrm{p}=0.000)$; I write good conclusions $(\mathrm{t}=4.351 ; \mathrm{p}=0.000)$; I take notes and use them in writing assignments $(\mathrm{t}=3.854 ; \mathrm{p}=0.000)$; I write a draft to logically organise my ideas $(\mathrm{t}=4.512 ; \mathrm{p}=0.000)$; and I edit my writing to improve the word choice, grammar, punctuation and spelling $(\mathrm{t}=3.647 ; \mathrm{p}=0.000)$. The only statement where no statistically significant difference was found was I write an appropriate summary of information I have read. All the other statements demonstrated more or less statistically significant differences between the two groups of the respondents.

The students were also asked to provide their opinion towards how language instructors should react to their final draft, e.g. which errors should be marked, 
corrected or commented on (Figure 2). The Lithuanian respondents preferred their language instructors to make comments on the structure $(78.8 \%)$, point out errors in the choice of lexical items $(75.8 \%)$, and point out errors in grammar $(75.7 \%)$, while the French respondents were most favourable towards comments on errors in grammar $(67.2 \%)$ followed by comments on the structure $(56.9 \%)$ and indication of errors in the choice of lexical items (56.9\%). Pointing out errors in punctuation (54.6\% Lithuanian and 32.8\% French) and comments on the ideas expressed $(62.2 \%$ Lithuanian and $43.1 \%$ French) were marked to be least important by both groups of students.

Statistically significant differences were observed between French and Lithuanian respondents' preferences for error correction in all types of feedback except for comments on the writing style and comments on the ideas expressed. Students' preferences for indication of errors in grammar $(t=2.625 ; p=0.010)$, errors in the choice of lexical items $(\mathrm{t}=2.718, \mathrm{p}=0.008)$ and comments on the structure $(t=3.031 ; p=0.003)$ were statistically significantly different between the two groups.

Point out errors in grammar (verb tenses, subject/verb agreement, article use, etc.)

Point out errors in the choice of lexical items

Make comments on the structure

Make comments on the writing style

Point out errors in spelling

Make comments on the ideas expressed

Point out errors in punctuation
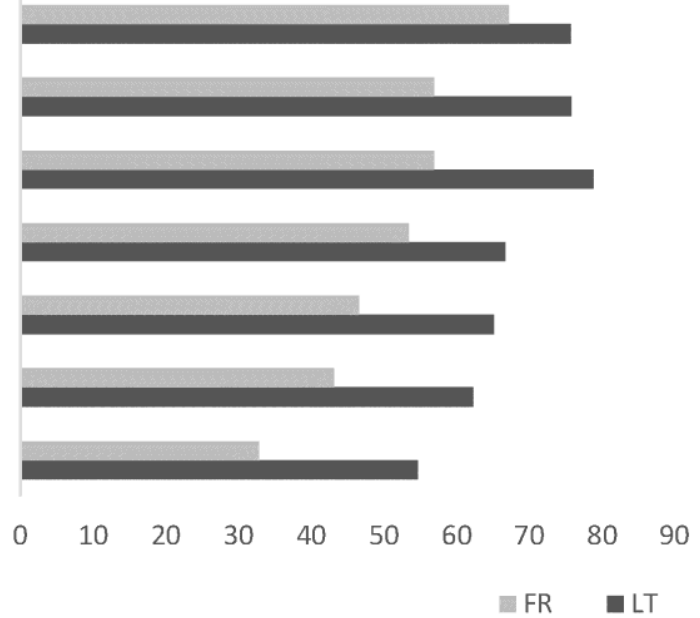

Figure 2. Preferred language instructor's feedback.

Figure 3 shows the respondents' preferences for written corrective feedback. The respondents of both groups were in favour of indirect feedback with a clue, i.e. they preferred their language instructors to show where the error was and give a clue how to correct it (56.1\% Lithuanian and 50\% French). Direct corrective feedback was preferred by $37.9 \%$ of the Lithuanian respondents and $36.2 \%$ of the French students. Indirect corrective feedback was favoured only by $6 \%$ of the Lithuanian respondents and $13.8 \%$ of the French students. Indirect corrective 
feedback with clarification request was not chosen as a possible type of feedback at all.

By showing where the error is and giving a clue about how to correct it

By crossing out what is incorrect and writing the correct word or structure

By only showing where the error is

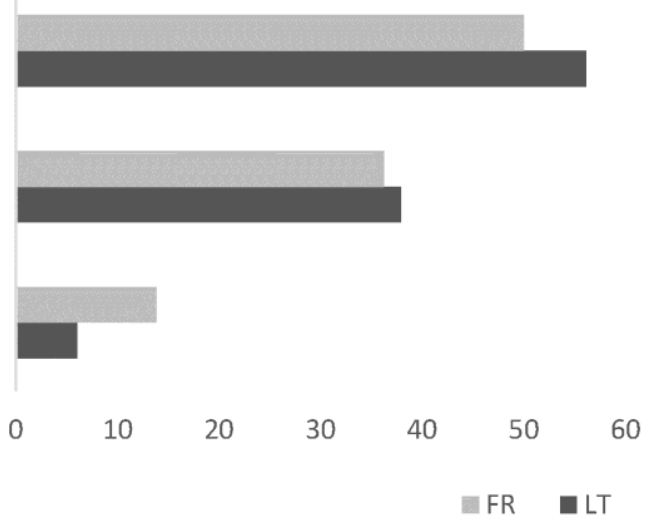

Figure 3. Respondents' preferences for written corrective feedback.

The respondents were also asked what they wanted their language instructor to do in case there were too many errors in their writing (Figure 4). The most favoured type of error marking in both groups was correction of all, major and minor, errors (42.4\% Lithuanian and 37.9\% French). The statement Correct all errors the language instructor considers major but not the minor ones $(24.2 \%$ Lithuanian and $27.6 \%$ French) was also frequently chosen. Other options were chosen rarely: Correct most but not necessarily all of the major errors $(13.6 \%$ Lithuanian and $12.1 \%$ French); Correct only errors that might interfere with expression of ideas $(4.5 \%$ Lithuanian and $13.8 \%$ French); Correct all repeated errors, major and minor (3\% Lithuanian and $8.6 \%$ French); and Correct only a few of the major errors (3\% Lithuanian). A small number of the Lithuanian respondents (7.6\%) also indicated other possibilities of error marking, e.g. specification of the main errors, just mentioning the minor ones, or asking to rewrite the text having received language instructor's advice. 
Correct all errors, major and minor

Correct all errors the teacher considers major, but not the minor ones

Correct most but not necessarily all of the major errors if there are many of them

Correct only a few of the major errors no matter how many there are

Correct all repeated errors whether major or minor

Correct only errors that might interfere with communicating your ideas

Other

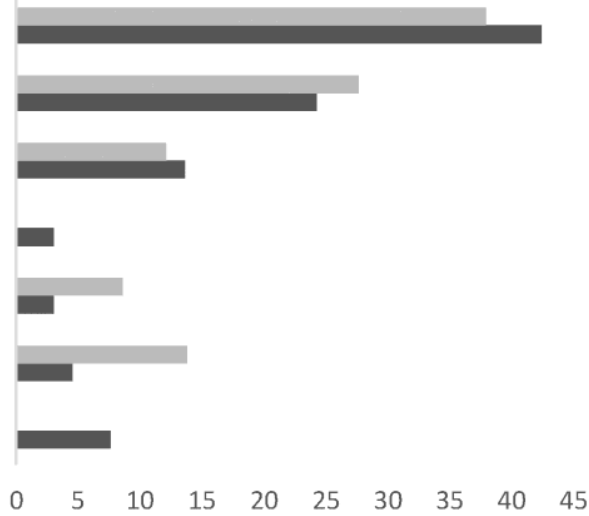

Figure 4. Respondents' preferences for types of errors to be indicated by a language instructor.

The Lithuanian and French respondents were asked how attentively they looked at language instructors' comments or corrections in their written texts (Figure 5). The respondents in both groups agreed that they read every comment attentively (51.5\% Lithuanian and 50\% French) and looked at some comments more carefully than at others (37.9\% Lithuanian and $43.1 \%$ French). The numbers of the respondents who chose to pay attention to comments on the ideas expressed in their written texts were lowest (10.6\% Lithuanian and 6.9\% French).

I read every one carefully

I look at some marks/comments more carefully than at others

I mainly pay attention to comments on the ideas expressed in the paper
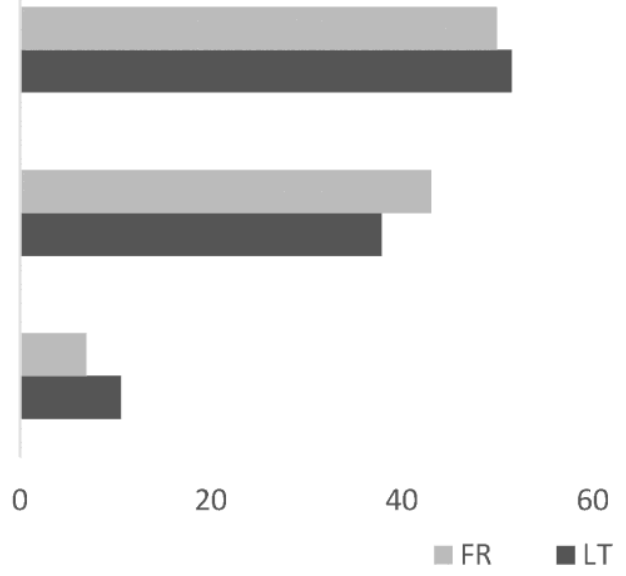

Figure 5. Respondents' engagement with corrective feedback provided by a language instructor. 
The results of the Student $t$ test for respondents' preferences for types of errors to be indicated by a language instructor and for respondents' engagement with provided corrective feedback did not demonstrate any statistically significant differences between the French and Lithuanian student groups.

According to the results obtained, it is evident that Lithuanian students often had writing assignments in their English classes: every class (10.6\%); every second class $(19.7 \%)$; once per week $(34.6 \%)$; once per two weeks $(31.8 \%)$; and rarely $(3 \%)$. Meanwhile, the French respondents indicated to have writing assignments in English classes rarely $(60.3 \%)$, once per two weeks $(27.6 \%)$; once per week $(12.1 \%)$, while every class or every second class options were not chosen by French respondents. Such results may be explained by the fact that French students on average have one EFL class per week, and because of time constraints writing assignments are infrequent.

One-way ANOVA was used to compare the mean scores of self-evaluation of writing skills and frequency of writing assignments in EFL classes in both groups of the respondents (N-66; N-58). The results demonstrated that self-evaluation of one writing skill was dependent on the frequency of writing assignments performed, i.e. reviewing the text and improving structure $(F=4.581 ; p=0.014)$ only in the group of the French respondents. The self-evaluation of other writing skills did not statistically significantly depend on the frequency of writing assignments in EFL classes. Moreover, there were no statistically significant differences found when comparing the mean scores of self-evaluation of writing skills and the frequency of writing assignments in EFL classes of the respondents' in the Lithuanian group.

\section{Discussion}

The results of this study indicate that the Lithuanian students who had EFL classes more intensively but for a shorter period of time, i.e. 5 hours per week for 6 months, evaluated their own writing skills better than French students who had their EFL classes for a longer period, i.e. an average of 2.5 hours per week for about 2.5 years. All Lithuanian students who take EFL classes were at level B2 at the beginning of the course; meanwhile, it is possible for French students to start their EFL classes at B1/B2 level. The Lithuanian students ranked highest their ability to write a logical topic sentence that identifies the topic and controlling idea of a summary, ability to support the main points, logical organisation of ideas, ability to support paragraphs with paraphrases, ability to paraphrase information and ability to write a draft to logically organise the ideas. The French students also ranked these abilities highest, but overall were less confident about their writing skills than the Lithuanian students. This might be explained by the difference in frequency of writing assignments in EFL classes as the majority of the French re- 
spondents $(60.3 \%)$ indicated that they rarely had writing assignments in comparison with $3 \%$ of the Lithuanian respondents.

Responses regarding the preferred language instructor's type of feedback were quite different as the majority of the French respondents preferred their language instructors to mark errors in grammar while the Lithuanian students mostly wanted comments on structure, choosing indication of grammar errors only as the third most favoured option, which may imply that the French students are more favourable towards corrective feedback than the Lithuanian students. In a study by Elwood and Bode (2014), corrective feedback was also found to be preferred by students.

The findings of the study also demonstrated that indirect feedback with revision clues was most favoured by both French and Lithuanian students followed by direct corrective feedback, which confirms the results obtained by Ferris and Roberts (2001). Indirect corrective feedback with no revision clues or clarification requests was a less preferred option, which is in line with Chandler's insights about the insufficiency or lack of information for learners to resolve complex errors (2003). Bitchener and Knoch (2010) advocated for direct corrective feedback, but indirect corrective feedback with a revision clue might engage students more actively in correction and, consequently, in understanding the error and avoiding it in future. The results on the student preferences for the type of corrective feedback obtained in the present study support the idea of promoting active learner engagement, which is to be best achieved through indirect corrective feedback with revision clues.

Another observation of the current study is that the French and Lithuanian respondents' preferences for types of errors to be indicated by a language instructor were almost the same, i.e. the majority of the students in both groups preferred all, major and minor, errors to be marked. This finding is in line with Leki's (1991) and Lee's (2005) results which showed the majority of respondents to favour the comprehensive approach towards error treatment. The only difference between the French and the Lithuanian students was in their preferences for correction of errors that might interfere with communicating ideas: French students chose this option as the third one, while there were only a few Lithuanian students to indicate it. However, this difference was statistically insignificant.

Zhao (2010) found that students tend not to closely examine the feedback, which is in disagreement with the results obtained in the present study where both Lithuanian and French respondents agreed that they read every comment attentively or looked at some comments more carefully than at others.

\section{Conclusion}

This study was focused on students' preferences for language instructor feedback as well as possible differences in self-evaluation of writing skills in different 
learning settings. The analysis of students' attitudes indicated that there were no associations between the frequency of writing assignments and self-evaluation of writing skills in Lithuanian and French student groups. The differences were obvious regarding the preferred language instructor's type of feedback as grammar error marking was most preferred by the French respondents while comments on structure were considered the most significant type of feedback by the Lithuanian students. Although the preferred type of feedback given by a language instructor seems to be different between the two groups under analysis, indirect corrective feedback with a clue is favoured by all the respondents.

A pedagogical implication stemming from this particular study might be the following: language instructors should acknowledge that relatively high proficiency students might be less favourable towards explicit corrections done by the instructor. Therefore, upon choosing indirect corrective feedback, language instructors should develop a mutual understanding with students as to the interpretation of error marking and clue giving, leading to increased student's awareness of the patterns of error types and effective correction of their own mistakes. Only accurate interpretation of instructor's clues may help to develop students' EFL proficiency.

One possible limitation to this study is the fact that students' proficiency was not measured as it might condition students' self-evaluation of writing skills to a certain extent. However, as the study was conducted upon or near to the completion of English as foreign language level C1, it may be assumed that the proficiency level of students who completed the questionnaire was similar in both groups and had little or no impact on the results of the study.

\section{Acknowledgements}

We kindly thank lecturer Michael O'Connor from Istia School of Engineering, University of Angers, for helping us with the distribution and collection of student questionnaires and for revising the language of the paper.

\section{References}

Ashwell, Tim. (2000). Patterns of teacher response to student writing in a multiple-draft composition classroom: Is content feedback followed by form feedback the best method? Journal of Second Language Writing 9.3: 227-257.

Bates, Linda, Janet Lane, Ellen Lange (1993). Writing clearly: responding to ESL compositions. Boston MA: Heinle and Heinle.

Beuningen, van Katherine (2010). Corrective feedback in L2 writing: theoretical perspective, empirical insights and future direction. International Journal of English Studies 10.2: 127. 
Bitchener, John, Ute Knoch (2010). Raising the linguistic accuracy level of advanced L2 writers with written corrective feedback. Journal of Second Language Writing 19.4: 207-217.

Bitchener, John (2008). Evidence in support of written corrective feedback. Journal of Second Language Writing 17: 102-108.

Bitchener, John, Stuart Young, Denise Cameron (2005). The effect of different types of corrective feedback on ESL student writing. Journal of Second Language Writing 14.3: 191-205.

Bruton, Anthony (2009). Improving accuracy is not the only reason for writing, and even if it were... System 37.4: 600-613.

Burt, Marina (1975). Error analysis in the adult ESL classroom. TESOL Quarterly 9.1: 53-63.

Chandler, Jean (2003). The efficacy of various kinds of error feedback for improvement in the accuracy and fluency of L2 student writing. Journal of Second Language Writing 12.3: 267-296.

Corder, Pit (1967). The significance of learner errors. International Review of Applied Linguistics 5.4: 161-169.

Diab, Rula L. (2005). EFL university students' preferences for error correction and teacher feedback on writing. TESL Reporter 38.1: 27-51.

Ellis, Rod, Younghee Sheen, Mihoko Murakami, Hide Takashima (2008). The effects of focused and unfocused written feedback in an English as a foreign language context. System 36.3: 353-371.

Elwood, James A., Jeroen Bode (2014). Student preferences vis-à-vis teacher feedback in university EFL writing classes in Japan. System 42: 333-343.

ESLP 82 Questionnaire: Self-assessment of English Writing Skills and Use of Writing Strategies. URL: www.marquette.edu/oie/documents/ESLP82QuestionnaireFa08. pdf (accessed 01/02/2016)

Ferris, Dana (2006). Does error feedback help student writers? New evidence on the shortand long-term effects of written error correction. In K. Hyland \& F. Hyland (eds.) Feedback in Second Language Writing: Contexts and Issues. New York: Cambridge University Press, 81-104.

Ferris, Dana (2002). Treatment of error in second language student writing. Michigan: The University of Michigan Press.

Ferris, Dana, \& Barrie Roberts (2001). Error feedback in L2 writing classes. How explicit does it need to be? Journal of Second Language Writing 10.3: 161-184.

Guenette, Danielle (2007). Is feedback pedagogically correct? Research design issues in studies of feedback on writing. Journal of Second Language Writing 16.1: 40-53.

Hartshorn, James K., Nowman W. Evans, Paul F. Merrill, Richard R. Sudweeks, Diane Strong-Krause, Neil J. Anderson (2010). Effects on Dynamic Corrective Feedback on ESL writing Accuracy. TESOL Quarterly 44.1: 84-109.

Harward, Stan, Nancy Peterson, Byran Korth, Jennifer Wimmer, Brad Wilcox, Timothy G. Morrison, Sharon Black, Sue Simmerman, Linda Pierce (2014). Writing instruction in elementary classrooms: why teachers engage or do not engage students in writing. Literacy research and instruction 53: 205-224.

Hyland, Fiona (2003). Focusing on form: student engagement with teacher feedback. System 31.2: $217-230$. 
Hyland, Fiona, Ye Han (2015). Exploring learner engagement with written corrective feedback in a Chinese tertiary EFL classroom. Journal of Second Language Writing 30: 31-44.

Kahraman, Ayhan, Fatma Yalvac (2015). EFL Turkish university students' preferences about teacher feedback and its importance. Procedia - Social and Behavioral Sciences 199: 73-80.

Jamalinesari, Ali, Farahnaz Rahimi, Hsbib Gowhary, Akbar Azizifar (2015). The effects of teacher written direct vs indirect feedback on students' writing. Procedia - Social and Behavioural Sciences 192: 116-123.

Lee, Icy. (2005). Error correction in L2 writing classroom: What do students think? TESL Canada Journal / Revu TESL du Canada 22.2: 1-16.

Lee, Icy (2004). Error correction in L2 secondary writing classrooms: The case of Hong Kong. Journal of Second Language Writing 13.4: 285-312.

Lee, Icy (2003). L2 writing teachers' perspectives, practices and problems regarding error feedback. Assessing Writing 8.3: 216-237.

Leki, Ilona (1991). The preferences of ESL students for error correction in college-level writing classes. Foreign Language Annals 24.3: 203-218

McMartin-Miller, Cristine (2014). How much feedback is enough? Instructor practices and student attitudes toward error treatment in second language writing. Assessing Writing 19: 24-35.

Pajares, Frank (2003). Self-efficacy beliefs, motivation, and achievement in writing: a review of the literature. Reading and Writing Quarterly 19.2: 139-158.

Sheen, Younghee (2007). The Effect of Focused Written Feedback and Language Aptitude on ESL learners' Acquisition of Articles. TESOL Quarterly 41.2: 255-283.

Truscott, John (1996). The case against grammar correction in L2 writing classes. Language Learning 46: 327-369.

Truscott, John (2007). The effect of error correction on learners' ability to write accurately. Journal of Second Language Writing 16.4: 255-272.

Zhao, Huahui (2010). Investigating learners' use and understanding of peer and teacher feedback on writing: a comparative study in a Chinese English writing classroom. Assessing Writing 15(1): 3-17.

Zumbrunn, Sharon, Sarah Mars, Caitlin Mewborn (2016). Toward a better understanding of student perceptions of written feedback: a mixed methods study. Reading and Writing 29.2: 349-370.

Authors' addresses:

Kaunas University of Technology

Faculty of Social Sciences, Arts and Humanities

Mickeviciaus 37-1309

44244 Kaunas, Lithuania

e-mail: jolita.horbacauskiene@ktu.lt

e-mail: ramune.kasperaviciene@ktu.lt

Received: December 13, 2016

Accepted for publication: December 19, 2016 